\title{
Pharmacological treatment of chronic obstructive pulmonary disease
}

\author{
Paolo Montuschi \\ Department of Pharmacology, Faculty \\ of Medicine, Catholic University of \\ the Sacred Heart, Rome, Italy
}

\begin{abstract}
None of the drugs currently available for chronic obstructive pulmonary disease (COPD) are able to reduce the progressive decline in lung function which is the hallmark of this disease. Smoking cessation is the only intervention that has proved effective. The current pharmacological treatment of COPD is symptomatic and is mainly based on bronchodilators, such as selective $\beta_{2}$-adrenergic agonists (short- and long-acting), anticholinergics, theophylline, or a combination of these drugs. Glucocorticoids are not generally recommended for patients with stable mild to moderate COPD due to their lack of efficacy, side effects, and high costs. However, glucocorticoids are recommended for severe COPD and frequent exacerbations of COPD. New pharmacological strategies for COPD need to be developed because the current treatment is inadequate.
\end{abstract}

Keywords: Chronic obstructive pulmonary disease, pharmacological treatment, bronchodilators, glucocorticoids, theophylline, antibiotics.

\section{Introduction}

The objective of pharmacological treatment of chronic obstructive pulmonary disease (COPD) is to prevent and control symptoms, reduce the frequency and severity of exacerbations, and improve general health status and exercise tolerance. None of the classes of drugs currently used in the treatment of COPD are able to modify the progressive decline in lung function which is the hallmark of this disease (Anthonisen et al 1994; Pauwels et al 1999; Vestbo et al 1999; Burge et al 2000). Smoking cessation is currently the only intervention which has been shown to reduce the progression of COPD (GICOPD 2001). To achieve this objective, behavioral therapy and pharmacological treatment such as the administration of bupropion (an antidepressant), and nicotine replacement therapy have proved useful (Jorenby et al 1999; Tashkin et al 2001). However, it is important to try to control symptoms of COPD with pharmacological treatment using the following general proposals (GICOPD 2001):

1) There should be a stepwise increase in treatment, according to the severity of the disease. The step-down approach used in the chronic treatment of asthma is not applicable to COPD.

2) Treatment needs to be chronic and maintained at the same level for long periods of time, unless significant side effects or exacerbations occur.

3) Since individual patient response to the pharmacological treatment is variable, it is important to monitor pharmacological treatment closely and, if necessary, adjust it frequently.

Drugs currently recommended for the treatment of COPD are:

1) Bronchodilators (selective $\beta_{2}$-agonists, anticholinergic antimuscarinic agents and methylxanthines);

2) glucocorticoids; 
3 ) other types of medication (vaccines, antibiotics, $\alpha_{1}$ - antitrypsin augmentation therapy, mucolytic agents, antioxidants, immunoregulators, antitussives and vasodilators).

These drugs will be presented in the order in which they would normally be prescribed for the treatment of patients with COPD, based on the level of severity of the disease. Current knowledge on inhibitors of phosphodiesterase type 4 (PDE4), a new class of drugs for COPD which are in the late phase III of clinical development (Lipworth 2005), will be presented. However, it must be emphasized that each treatment regimen needs to be patient-specific as the relationship between the severity of symptoms and the severity of lung function is influenced by other factors, such as the frequency and severity of exacerbations, the presence of complications, the presence of respiratory failure, the presence of other diseases, and general health status.

\section{Treatment of stable chronic obstructive pulmonary disease Bronchodilators}

Bronchodilators are currently the mainstay of the treatment of COPD (GICOPD 2001). Bronchodilators are selective short-acting $\beta_{2}$-agonists such as salbutamol, metaproterenol, terbutaline, bambuterol, pirbuterol, isoetharine, bitolterol and fenoterol or selective long-acting $\beta_{2}$-agonists such as salmeterol and formoterol; anticholinergic antimuscarinic agents such as ipratropium bromide, oxitropium bromide and tiotropium bromide, and methylxanthines such as theophylline. Short- and long-acting $\beta_{2}$-agonists and antimuscarinic agents are generally administered by inhalation (aerosol, dry-powder or nebuliser solution). Bronchodilator therapy is most frequently delivered by pressurized metered-dose inhalers (MDIs) or dry-powder inhalers (DPIs). Because of the lower bioavailability in asthma patients, the dose delivered by DPIs should be doubled compared with that of MDIs (RS 2003); while a study comparing ipratropium bromide delivered by MDIs and by DPIs in COPD patients found that there was no difference between these two types of inhalers (Cuvelier et al 2002). The use of a spacer device to improve drug delivery proves particularly useful for patients who have poor inhalation technique. In a study on patients with COPD, inhalation of salbutamol through MDIs with spacer and dry-powder inhalers produced similar bronchodilating effects (Ikeda et al 1999). However, further studies are necessary to establish deposition in the respiratory tract and the dose-effect relationship of drugs delivered by different inhalers in patients with COPD, as these are important factors in the choice of dosage. Short-acting $\beta_{2}$-agonists such as salbutamol and terbutaline are also available for oral or parenteral delivery. Theophylline is generally administered orally, mostly frequently in controlled release preparations which prolong the pharmacological effect of the drug, even if they do not significantly eliminate the interindividual variability of the bioavailability. For chronic administration, bronchodilators are the mainstay of treatment of COPD as they prevent and improve symptoms (Chrystyn et al 1988; Vathenen et al 1988; Gross et al 1989; Rennard 2004). One of the main therapeutic effects of bronchodilators, at least in severe COPD, is improvement in the emptying of the lungs during expiration. This causes a reduction in dynamic hyperinflation at rest and during exercise with consequent improvement in exercise tolerance (Belman et al 1996). However, it is not easy to predict the extent of this improvement based on an increase in forced expiratory volume in one second $\left(\mathrm{FEV}_{1}\right)$ after a short period of bronchodilatory therapy (Berger and Smith 1988; Hay et al 1992). The evaluation of the efficacy of bronchodilators is generally based on questionnaires concerning symptom variation. COPD may require inhalation of a short-acting $\beta_{2}$-agonist on demand or, when airways obstruction is more severe, chronic administration of an antimuscarinic agent by inhalation or a long-acting $\beta_{2}$-agonist (RS 2003).

\section{Selective $\beta_{2}$-agonists}

There are no significant differences between the various $\beta_{2}$-agonists as far as selectivity for $\beta_{2}$-adrenoceptors is concerned, with the exception of metaproterenol and iso-etharine, which are less selective (Undem and 12001 ). Short-acting $\beta_{2}$-agonists have a bronchodilatory effect within 1 to 5 minutes and which lasts for up to 4 hours (Rennard 2004). Long-acting inhaled $\beta_{2}$-adrenergic agonists such as salmeterol and formoterol have a prolonged bronchodilatory effect for approximately 12 hours. Unlike salmeterol which has a slow onset of action, formoterol has a rapidly occurring bronchodilatory effect similar to that of shortacting $\beta_{2}$-agonists (Undem and Lichtenstein 2001; Rennard 2004). Selective $\beta_{2}$-agonists mainly work by stimulating the $\beta_{2}$-adrenoceptors on the airway smooth muscle cells. The formation of the drug-receptor complex activates a stimulatory protein (Gs) which binds to guanosine triphosphate (GTP) with activation of the adenylate cyclase which leads to an increase in intracellular cyclic adenosine 
monophosphate (cAMP) levels which, in turn, activates a cAMP-dependant protein kinase (PKA) (Johnson and Coleman 1995). Activation of the latter causes myosin light chain kinase phosphorylation with a reduction in the affinity of this enzyme for the calcium-calmodulin complex, a reduction in the formation of active myosin light chain kinase, a reduction in myosin phosphorylation and, finally, a reduction in the interaction of actin and myosin filaments with consequent bronchodilation. In addition, PKA stimulation causes a reduction in intracellular calcium ion levels because of increased extrusion of calcium from the cell, reduction in the entry of calcium into the cell, and increase in the uptake of calcium by the smooth endoplasmic reticulum, which is the site at which calcium ions are deposited within the cell.

The reduction in the concentration of intracellular calcium causes a reduction in the formation of the calcium-calmodulin complex which produces the previously described effects. In addition to this main bronchodilation mechanism of selective $\beta_{2}$-agonists, other mechanisms may, in theory, contribute to reducing airway obstruction. Stimulation of $\beta_{2}$-adrenoceptors also increases potassium channel conduction with hyperpolarization and relaxation of the airway smooth muscle (Kume et al 1994). This effect is, in part, independent from the increase in cAMP levels (Kume et al 1994). The activation of $\beta_{2}$-receptors on inflammatory cells such as mast cells, basophils, eosinophils, neutrophils and lymphocytes cause an increase in cAMP levels and subsequent inhibition of the release of inflammatory mediators such as leukotrienes, histamine and cytokines (Hughes et al 1983; Barnes 1999). $\beta_{2}$-agonists increase mucociliary clearance, decrease microvascular permeability and may inhibit phospholipase $A_{2}$ with subsequent reduction in the synthesis of leukotrienes, prostaglandins and thromboxane $\mathrm{A}_{2}$, which are important inflammatory mediators (Seale 1988). The importance of these mechanisms on the therapeutic effect of $\beta_{2}$-agonists in humans, particularly in COPD, is not known.

Inhalation limits the absorption and therefore the systematic side effects of $\beta_{2}$-agonists. However, only about $10 \%$ of the aerosol enters the respiratory tract while the remainder is swallowed and may be absorbed in the intestinal tract with consequent systemic side effects. Furthermore, aerosolized particles less than $1 \mu \mathrm{m}$ in diameter reach the alveoli and may be absorbed in the pulmonary capillaries. The main side effect of selective $\beta_{2}$-agonists administered by inhalation at clinical doses is muscular tremor. However, this tends to diminish in intensity during prolonged treatment. This phenomenon is known as drug tolerance. It is not know if drug tolerance is due to the down regulation of the $\beta_{2}$-adrenoceptors on the muscle cytoskeleton or to adaptation phenomena in the central nervous system. Tachycardia is uncommon in clinical doses of $\beta_{2}$-agonists administered by inhalation. The absorption of $\beta_{2}$-agonists may cause tachycardia by stimulating the cardiac $\beta_{1}$-adrenoceptors, particularly at higher doses when relative selectivity for $\beta_{2}$-adrenoceptors is lost. Although there are fewer cardiac $\beta_{2}$-adrenoceptors, their stimulation may also contribute to tachycardia (Undem and Lichtenstein 2001). This type of side effect is particularly relevant in patients with ischemic heart disease or preexisting arrhythmias. In these patients, $\beta_{2}$-agonists need to be administered with caution, even when inhaled. Bronchodilation may cause ventilation/perfusion mismatch with a consequent drop in the arterial partial pressure of oxygen. This is generally transitory and of little importance. Other side effects of systemically delivered $\beta_{2}$-agonists, such as hypokalemia, increase in the plasma concentrations of glucose, lactose, and free fatty acids are much less common when $\beta_{2}$-agonists are delivered by inhalation.

\section{Antimuscarinic drugs}

Antimuscarinics are delivered in the same way as bronchodilators. Antimuscarinics are quaternary ammonium derivatives which, after inhalation, undergo $<1 \%$ absorption from the pulmonary or gastrointestinal tract. The parasympathetic nervous system has a role in the regulation of the bronchial tone. Vagal fibres activate nicotinic and $M_{1}$ muscarinic receptors on the parasympathetic ganglia of the respiratory tract; short postganglionic fibers release acetylcholine which stimulates the $\mathrm{M}_{3}$ muscarinic receptors on the airway smooth muscle cells with consequent increase in motility. In addition, the airway submucosal glands have $M_{3}$ muscarinic receptors. $M_{3}$ muscarinic receptor stimulation increases bronchial secretion. Inflammatory mediators such as eicosanoids, histamine, and bradykinin may further produce parasympathetic reflexes which partly explains their bronchoconstriction effect. Antimuscarinic bronchodilators are non-selective antagonists of cholinergic muscarinic receptors. Their effect on airway obstruction is mainly due both to $\mathrm{M}_{3}$ muscarinic receptor antagonism in the airway smooth muscle cells, with consequent bronchodilation, and to $M_{3}$ muscarinic receptor antagonism in the cells of the submucosal glands, with a reduction in the basal and stimulated cholinergic 
parasympathetic activity with consequent reduction in airway obstruction. Unlike atropine, antimuscarinic bronchodilators do not have an inhibitory effect on mucociliary clearance. The reason for this difference is not known. The effectiveness of antimuscarinic drugs depends on the role that cholinergic vagal tone has in the pathophysiology of bronchial obstruction. Antimuscarinic bronchodilators are generally considered to be more effective for COPD than for asthma. This could be partly due to the different pathophysiological role of the parasympathetic vagal system in these two diseases. The aerosol inhalation of ipratropium has a maximum effect 30-60 minutes after administration; its duration of action is 3 to 6 hours, making administration of the drug necessary 3 to 4 times a day. Ipratropium generally produces the same moderate bronchodilation as obtained with maximum doses of $\beta_{2}$-agonists (Undem and Lichenstein 2001). Oxitropium produces similar pharmacological effects to ipratropium and can be administered twice a day. Tiotropium bromide, a new long-acting anticholinergic drug, which can be administered just once a day, has similar or greater efficacy compared with other bronchodilators (Calverley 2000) and is useful in combination with formoterol for COPD treatment (van Noord et al 2006). A randomized, prospective, double-blind, placebo-controlled, multicenter trial to assess whether adding salmeterol or salmeterolfluticasone to chronic therapy with tiotropium would provide additional clinical benefit to patients with moderate to severe COPD is currently being carried out (Aaron et al 2004). Tiotropium improves sleeping arterial oxygen saturation (McNicholas et al 2004) and, in combination with pulmonary rehabilitation, exercise tolerance in patients with COPD (Casaburi et al 2005). Tiotropium bromide is indicated in the maintenance treatment of COPD, but it is not effective in relieving acute bronchospasms. However, as is the case with asthmatic patients, some authors raised doubts about chronic administration of bronchodilators which could be associated with worsening COPD (van Schayck et al 1991). Because of their negligible absorption, antimuscarinics rarely cause systemic side effects and are generally well tolerated. Possible side effects include dry mouth, nausea, constipation, and headache (RS 2003). Antimuscarinic bronchodilators should be administered with caution in glaucoma, benign prostatic hypertrophy and urinary obstruction (RS 2003; Rennard 2004). Cases of acute angle-closure glaucoma have been reported with nebulized ipratropium, particularly when given with nebulized salbutamol.

\section{Theophylline}

Theophylline, a methylxanthine, is one of the least expensive bronchodilators. Given its very low solubility in water, theophylline is administered intravenously as aminophylline. Aminophylline is a theophylline and ethylenediamine mixture, which is 20 times more soluble than theophylline alone. The bronchodilatory effect of theophylline is due both to relatively non-selective inhibition of cyclic neucleotide phosphodiesterases and to competitive antagonism of adenosine receptors (Barnes 2003). At least eleven phosphodiesterase isozymes have been identified (Soderling and Beavo 2000). The inhibition of phosphodiesterase isozymes type III and IV causes relaxation of the airway smooth muscle cells in vitro (Torphy et al 1993). Selective phosphodiesterase-4 inhibitors for COPD are currently in clinical trials (Lipworth 2005). Adenosine receptor antagonism also contributes to the brochodilatory effect of theophylline (Feoktistov et al 1998). In addition to bronchodilation, theophylline may have anti-inflammatory effects at lower plasma concentrations in the respiratory tract as shown by the reduction both in the number of neutrophils and in the interleukin-8 concentration in induced sputum from COPD patients, where the same effects cannot be obtained after inhalation of high glucocorticoid doses (Barnes 2003). In vitro studies have shown that low doses of theophylline may enhance the anti-inflammatory effect of corticosteroids and antagonize the "resistance" to corticosteroids caused by smoking in COPD patients by activating histone deacetylases (Barnes 2003, 2006).

Theophylline is generally administered orally in conventional form or, more frequently, through sustainedrelease preparations or intravenously (like aminophylline) (Undem and Lichtenstein 2001). Sustained-release preparations are available for administration every 8,12 , or 24 hours. Intravenous administration of theophylline must be given very slowly, over at least a 20 minute period (RS 2003), because of the risk of serious toxic effects such as arrhythmias and convulsions. Inhalation of theophylline is not effective and intramuscular injection is not possible because of its irritant effect at the site of injection. Absorption of theophylline from conventional formulations is fast and complete with a plasma concentration peak within two hours of administration. Absorption of theophylline from sustained-release preparations has a large interindividual variability, for this reason, dosage must be changed to suit the individual patient. Theophylline is mainly eliminated by hepatic 
metabolism (less than $15 \%$ is excreted in the urine unchanged) (Undem and Lichtenstein 2001). There is wide variation in the rate of elimination of theophylline. The half-life of elimination is on average 8 to 9 hours in adults and about 3.5 hours in children (Undem and Lichtenstein 2001). The half-life is increased in heart or liver failure, viral infections, in the elderly and with concomitant administration of some drugs such as cimetidine, ciprofloxacin, erythromycin, fluvoxamine, and oral contraceptives. The half-life of elimination of theophylline is decreased in smokers and in chronic alcoholics, and with concomitant administration of drugs such as phenytoin, carbamazepine, rifampicin, and barbiturates (RS 2003). In addition to bronchodilation, theophylline may increase cardiac contractility, have a psychostimulant or diuretic effect, and increase diaphragmic contractility. A possible therapeutic importance for COPD has been attributed to this last effect. However, theophylline has some disadvantages including its low therapeutic index which limits its administration. For this reason, and because of the large interindividual variability in its bioavailability, therapeutic monitoring of plasma theophylline concentrations is required. This involves taking regular blood samples after the theophylline concentrations reach a steady-state to ensure that the plasma theophylline concentration is within the therapeutic range for plasma theophylline concentrations for which the majority of patients obtain therapeutic effects without toxic effects, even though side effects are found with therapeutic concentrations. The therapeutic range for theophylline is between $10-20 \mu \mathrm{g} / \mathrm{ml}$. Toxic side effects are associated with theophylline concentrations of more than $25 \mu \mathrm{g} / \mathrm{ml}$. The risk of serious toxic effects, such as arrhythmias and convulsions, is high with theophylline concentrations of more than $40 \mu \mathrm{g} / \mathrm{ml}$. At therapeutic plasma concentrations the main side effects of theophylline include anorexia, nausea, vomiting, insomnia, agitation, palpitation, and hypotension (Undem and Lichtenstein 2001).

\section{Glucocorticoids}

Inhaled glucocorticoids currently available include beclomethasone dipropionate, budesonide, flunisolide, fluticasone propionate and triamcinolone acetonide. There are no significant differences between these drugs in terms of their efficacy and tolerability (Undem and Lichtenstein 2001; RS 2003). Mometasone and ciclesonide, two new glucocorticoids in advanced clinical trials, seem to have a longer duration of action with the possibility of once a day administration. Ciclesonide is a prodrug which is activated by a pulmonary esterase, with the possibility of increased selectivity of action and reduced systemic side effects resulting from glucocorticoid absorption. Glucocorticoids do not cause relaxation of the airway smooth muscle and therefore have no effect on acute bronchoconstriction. Glucocorticoids bind to specific cytoplasmic receptor proteins, which, in turn bind to regulatory proteins such as heat shock proteins and an immunophyllin (Undem and Lichtenstein 2001). The glucocorticoid-receptor interaction causes a receptor conformational change which leads to regulatory protein detachment, dimerization of the glucocorticoid receptor complexes and translocation to the nucleus where the drug-receptor complex binds to specific regulatory DNA sequences (glucocorticoid response elements, GRE), which modulate the expression of the adjacent genes. The time required for gene expression and protein synthesis explains the delayed effect of glucocorticoids which generally occurs several hours after administration. The anti-inflammatory mechanisms of action of glucocorticoids are largely due to the inhibition of gene expression which encodes for proinflammatory cytokines in the airway inflammatory cells (Undem and Lichtenstein 2001). Part of the anti-inflammatory effect of glucocorticoids may be due to the induction of lipocortin. Lipocortin is a protein which inhibits phospholipase $A_{2}$. Phospholipase $A_{2}$ enzymes cause cleavage of arachidonic acid from phospholipids in the plasma membrane. The arachidonic acid is the substrate for the synthesis of leukotrienes, prostaglandins, and thromboxane $\mathrm{A}_{2}$, which are important inflammatory mediators. Although glucocorticoids are generally effective in asthma, the anti-inflammatory effect of glucocorticoids in COPD patients remains controversial and seems to be very limited (Pauwels et al 1999; Vestbo et al 1999; Burge et al 2000; LHSRG 2000). This seems to reflect a pathophysiological difference between COPD and asthma. It has been suggested, on the basis of in vitro studies, that oxidative stress and cigarette smoke, which both play an important role in the pathophysiology of COPD, induce resistance to the action of glucocorticoids through mechanisms which involve the acetylation of histones. Histones are nucleic proteins that are important regulators in gene expression (Barnes 2000, 2003). Furthermore, the variable effects of glucocorticoids on airway inflammation may be due to the heterogeneity of the disease and the limited reproducibility of markers of inflammation (Keatings et al 1997; Confalonieri et al 1998). What is 


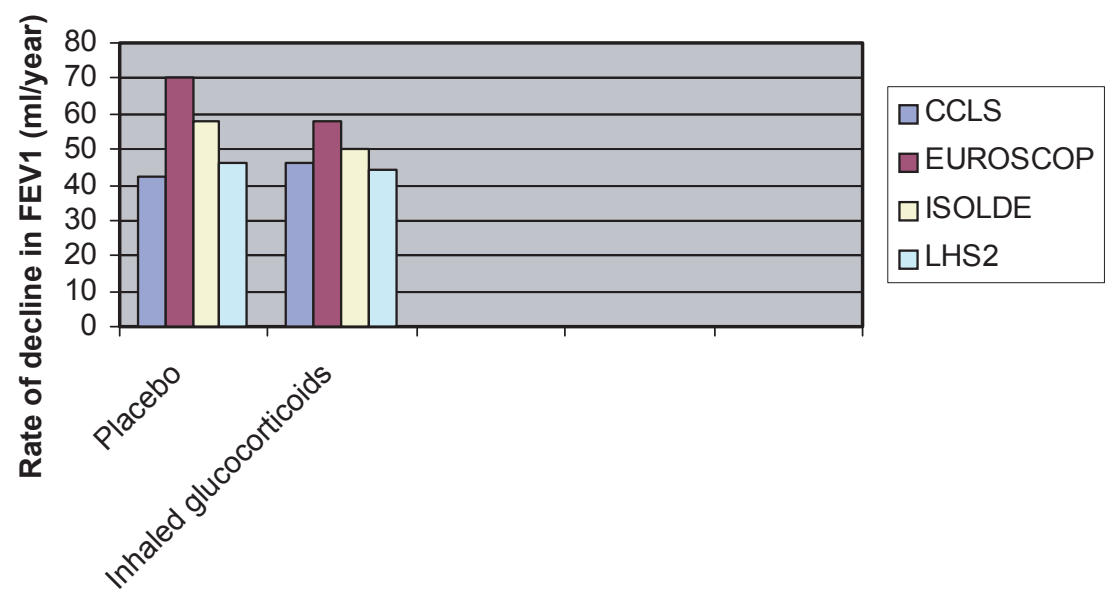

Figure I Rate of decline in forced expiratory volume in one second (FEV, after administration of placebo or inhaled glucocorticoids in four randomized controlled multicenter clinical trials: Copenhagen City Lung Study (CCLS), European Respiratory Society study On Chronic Obstructive Pulmonary disease (EUROSCOP), Inhaled Steroids in Obstructive Lung Disease (ISOLDE), and Lung Health Study 2 (LHS2). Inhaled glucocorticoids did not have a significant effect on the rate of decline in FEV in any of the clinical trials.

certain is that glucocorticoids do not modify the natural history of COPD, as measured by the rate of decline in $\mathrm{FEV}_{1}$ (Figure 1). Four large randomized placebocontrolled multicenter clinical trials (European Respiratory Society study on chronic obstructive pulmonary disease [EUROSCOP], Copenhagen City Lung Study, Inhaled Steroids in Obstructive Lung Disease in Europe [ISOLDE], and Lung Health Study 2 [Pauwels et al 1999; Vestbo et al 1999; Burge et al 2000; LHSRG 2000]) all found that inhaled glucocorticoids had no significant effects on the progressive decline in $\mathrm{FEV}_{1}$ in patients with mild and moderate to severe COPD. One of these studies (Burge et al 2000) in patients with more severe COPD showed a reduction in the frequency of exacerbations (from 1.33 to 0.99 per year, a reduction of $25 \%$ ). Other clinical trials with both fluticasone and budesonide showed that inhaled glucocorticoids reduce COPD exacerbation rate (Calverley, Pauwels, et al 2003; Jones et al 2003; Szafranski et al 2003), although the mechanism for this effect is currently unknown. However, an earlier study on a smaller sample showed a reduction in severity, but not in the frequency of exacerbations with inhaled glucocorticoids (Paggiaro et al 1998). From these clinical trials it is concluded that inhaled glucocorticoids should only be administered to patients with severe to very severe COPD (post-bronchodilator FEV $\leq 50 \%$ of the predicted value) with frequent exacerbations requiring treatment with antibiotics or oral glucocorticoids (GICOPD 2001). The dose of glucocorticoids required to reduce the frequency of exacerbations in these patients with COPD is not known (MacNee and Calverley 2003).

Improvement in airflow in patients with COPD after chronic treatment with inhaled glucocorticoids is very modest (Pauwels et al 1999; Burge et al 2000). However, some studies reported further improvement in airflow when glucocorticoids are added to long-acting $\beta_{2}$-agonist bronchodilators (Mahler et al 2002; Calverley, Pauwels, et al 2003; Szafranski et al 2003).

One study reported that withdrawal of fluticasone propionate from combined salmeterol-fluticasone treatment in patients with COPD resulted in acute and persistent deterioration in lung function and dyspnoea and in increase in mild exacerbations (Wouters et al 2005). However, median percentage predicted $\mathrm{FEV}_{1}$ at start of the 3 month run-in period was about $50 \%$ implying that a considerable number of patients included in this study had moderate COPD ( $\mathrm{FEV}_{1} \geq 50 \%$ of the predicted value) for which inhaled glucocorticoids are not indicated (GICOPD 2001). On the other hand, all the patients in this study had a history of at least 2 COPD exacerbations in the last year treated with oral glucocorticoids and/or antibiotics which suggest chronic treatment with inhaled glucocorticoids (GICOPD 2001).

The effect of inhaled glucocorticoids on mortality for COPD is controversial and mainly based on retrospective data (Sin and Tu 2001; Soriano et al 2002; Fan et al 2003; Suissa 2003; Sin et al 2005). Prospective studies assessing the effect of inhaled glucocorticoids and longacting $\beta_{2}$-agonists, alone or in combination, on mortality in patients with COPD are in progress (Rennard 2004; Vestbo 2004).

Oral glucocorticoids are not generally recommended for the treatment of stable COPD due to their limited therapeutic effects and numerous systemic side effects. 
Administration of inhaled glucocorticoids for patients with stable COPD must again be carefully considered because of possible side effects. Oropharyngeal candidiasis, due to the local immunosuppressive effect of glucocorticoids, is a common side effect. Oropharyngeal candidiasis is avoidable to a certain extent by using large volume spacers or rinsing the oropharynx with water after drug delivery. Even when delivered locally, such as by aerosolized inhaler, glucocorticoids may be partly absorbed with consequent systemic side effects due to their high lipid solubility. Particularly notable side effects include suppression of endogenous cortisol synthesis by inhibiting the hypothalamic-pituitary-adrenal axis, particularly at doses higher than $1500 \mu \mathrm{g} /$ day (Undem and Lichtenstein 2001); the possibility of osteoporosis even at doses of $500 \mu \mathrm{g} /$ day (Undem and Lichtenstein 2001); a slightly increased risk of glaucoma, particularly during long-term treatment at high doses, and of cataract (Undem and Lichtenstein 2001). Glucocorticoids, particularly at high doses, should be inhaled using a large-volume spacer which increases the profound deposition of the drug and reduces drug deposition in the oropharynx, with a consequent reduction in the incidence of candidiasis. However, in the absence of proven efficacy and because of possible side effects, including systemic side effects, and high costs, there is no rational pharmacological basis for the use of inhaled glucocorticoids for all patients with stable COPD, and their use should be limited just to the cases previously described (GICOPD 2001).

\section{Clinical considerations}

The choice between $\beta_{2}$-agonists, anticholinergic antimuscarinic agents, theophylline or drug combinations depends on individual patient response to the treatment. Pharmacological therapy at each stage of stable COPD according to Global Initiative for Chronic Obstructive Lung Disease (GOLD) guidelines is shown in Figure 2 (Figure 2). Bronchodilator combinations may improve drug efficacy and reduce side effects, compared with an increase in the dosage of a single bronchodilator (COMBIVENT 1994).

For patients with COPD, long-acting $\beta_{2}$-agonists delivered by inhalation, such as salmeterol and formoterol,

\begin{tabular}{|c|c|c|c|c|c|}
\hline New & 0: At Risk & I: Mild & II: Moderate & III: Severe & IV: Very Severe \\
\hline Characteristics & $\begin{array}{l}\text { - Chronic symptoms } \\
\text { - Exposure to risk } \\
\text { factors } \\
\text { - Normal spirometry }\end{array}$ & $\begin{array}{l}\text { - } \mathrm{FEV}_{\mathrm{I}} \mathrm{FVC}<70 \% \\
\text { - } \mathrm{FEV}_{2} \geq 80 \% \\
\text { - With or without } \\
\text { symptoms }\end{array}$ & $\begin{array}{l}\text { - } \mathrm{FEV}_{1} / \mathrm{FVC}<70 \% \\
\text { - } 50 \% \leq \mathrm{FEV}_{1}<80 \% \\
\text { - With or without } \\
\text { symptoms }\end{array}$ & $\begin{array}{l}\text { - } \mathrm{FEV}_{1} / \mathrm{FVC}<70 \% \\
\text { - } 30 \% \leq \mathrm{FEV}_{1}<50 \% \\
\text { - With or without } \\
\text { symptoms }\end{array}$ & $\begin{array}{l}\text { - } \mathrm{FEV}_{1}, \mathrm{FVC}<70 \% \\
\text { - } \mathrm{FEV}_{1}<30 \% \text { or } \mathrm{FEV}_{1}<50 \% \\
\text { predicted plus chronic } \\
\text { respiratory failure }\end{array}$ \\
\hline & \multicolumn{5}{|c|}{ Avoidance of risk factor(s); influenza vaccination } \\
\hline & & \multicolumn{4}{|c|}{ Add short-acting bronchodilator when needed } \\
\hline & & & \multicolumn{3}{|c|}{$\begin{array}{l}\text { Add regular treatment with one or more } \\
\text { long-acting bronchodilators } \\
\text { Add rehabilitation }\end{array}$} \\
\hline & & & & \multicolumn{2}{|c|}{$\begin{array}{l}\text { Add inhaled glucocorticosteroids } \\
\text { if repeated exacerbations }\end{array}$} \\
\hline & & & & & $\begin{array}{l}\text { Add long-term } \\
\text { oxygen if chronic } \\
\text { respiratory } \\
\text { failure } \\
\text { Consider surgical } \\
\text { treatments }\end{array}$ \\
\hline
\end{tabular}

Figure 2 Pharmacological treatment of stable COPD based on GOLD guidelines. Adapted from GICOPD (200I). 
significantly improve symptoms, exercise tolerance and general health status (Cazzola et al 1995; Ulrik 1995; Boyd et al 1997). Both $\beta_{2}$-agonists and long-acting anticholinergics reduce the frequency of exacerbations in COPD (Rennard et al 2001; Casaburi et al 2002) although the mechanism(s) of this effect is currently unknown. Possible antiinflammatory effects of long-acting $\beta_{2}$-agonists (Johnson and Rennard 2001) might explain the reduced frequency of exacerbations of COPD (Mahler et al 1999; Rennard et al 2001; Calverley, Pauwels, et al 2003). These bronchodilators do not seem to cause tachyphylaxis, namely rapid reduction in the intensity of the pharmacological effect due to continued or repeated administration, and are well tolerated. Although bronchodilator treatment in COPD is generally started with a single agent, the use bronchodilators in combination is suggested in the current guidelines as this strategy can result in improved bronchodilator and clinical effect (GICOPD 2001; Celli and McNee 2004). However, the interindividual variability of the bronchodilating effect can be high. The efficacy of combining either short or long-acting $\beta_{2}$-agonists with anticholinergics (COMBIVENT 1994; van Noord et al 2000, 2006), anticholinergics and theophylline (Bleecker and Britt 1991; Bellia et al 2002), and all three classes of bronchodilators is known (Nishimura et al 1995). A fixed inhaled combination of albuterol and ipratropium is available.

High doses of nebulized bronchodilators are still widely prescribed for severe COPD. The British Thoracic Society (BTS) guidelines on nebulizer therapy (NPG 1997) recommend that a respiratory physician should evaluate the effectiveness of nebulizer therapy. Before trying chronic nebulizer therapy, it is advisable to evaluate the efficacy of high dose bronchodilator treatment delivered by metered dose inhaler (MDI) with a spacer. The administration of theophylline for stable COPD remains controversial. Theophylline causes bronchodilation in COPD (Murciano et al 1989; McKay et al 1993) with a variable effect on exercise tolerance and symptoms (Murciano et al 1984; Cooper et al 1987; Chrystyn 1988; Mulloy and McNicholas 1993). Theophylline has a slow onset of action and it is generally recommended for maintenance treatment, rather than for the rapid treatment of symptoms. In the major guidelines for the treatment of COPD, theophylline is considered a third line bronchodilator after inhaled anticholinergics and $\beta_{2}$ agonists (Barnes 2006). Nevertheless, theophylline is a useful treatment in patients with severe COPD as its withdrawal leads to significant clinical worsening of the disease (Kirsten DK 1993). The most recent and largely selective phosphodiesterase inhibitors, such as inhibitors of phosphodiesterase type 4 isoenzyme, slightly improve lung function in COPD (Compton et al 2001) and reduce the frequency of exacerbations (Edelson et al 2001; Rabe et al 2005; Rennard et al 2006) (see below). However, further studies are needed to adequately evaluate the efficacy and tolerability of this new class of drugs.

Long-acting bronchodilators administered once or twice daily can improve symptoms to the same extent or more compared with chronic administration of short-acting bronchodilators. For this reason it is possible to consider the use of long-acting bronchodilators for the treatment of COPD patients requiring chronic treatment to improve symptoms. Theophylline may be recommended for patients with persistent symptoms instead of long-acting bronchodilator treatment. However, because of the disadvantages outlined above, administration of theophylline should be continued only if its efficacy on the symptoms has been demonstrated. The role of theophylline in the treatment of COPD is currently being re-evaluated based on important pharmacological evidence which has allowed the molecular mechanism of action of theophylline to be clarified (Barnes 2003).

Inhaled glucocorticoids are generally prescribed for COPD without demonstration of their effectiveness. However, COPD patients generally have no, or a negligible, response to glucocorticoids (Pauwels et al 1999; Vestbo et al 1999; Burge et al 2000; LHSRG 2000; RS 2003). Some patients may improve after glucocorticoid treatment, but it is likely that these patients have concomitant asthma (Barnes 2000). A two-week trial of oral glucocorticoids was proposed to identify patients with a documented spirometric response, assuming that an acute response is predictive of a chronic response (GISCOPD 2001). However, the oral administration of glucocoticoids for two weeks does not generally allow identification of those patients who will respond to inhaled glucocorticoids (Senderovitz et al 1999; Burge et al 2000, 2003). Therefore, a trial of glucocorticoids is not generally recommended for COPD (GISCOPD 2001), unless required to exclude asthma (Barnes 2000). Glucocorticoids do not reduce airway inflammation in COPD (Barnes 2000) and various long-term studies showed that glucocorticoids are not able to reduce the progression of COPD (Pauwels et al 1999; Vestbo et al 1999; Burge et al 2000; LHSRG 2000). For this reason, and taking into account the risk of systemic side effects, particularly at high doses, glucocorticoids should not generally be administered for COPD (Barnes 2000), though they are recommended 
for the treatment of exacerbations. Furthermore, inhaled glucocorticoids are recommended for symptomatic COPD patients who have a documented spirometric response to these drugs or for patients with $\mathrm{FEV}_{1} \leq 50 \%$ of the predicted value and frequent exacerbations (two or more per year), which require antibiotics or oral glucocorticoids, according to the GOLD guidelines (GISCOPD 2001). However, these recommendations are not universally agreed (Barnes 2000), as the effect of inhaled glucocorticoids at high doses on the frequency of exacerbations in patients with severe COPD is controversial (Paggiaro et al 1998; Burge et al 2000). Furthermore, the cost of glucocorticoids as well as their pharmacological profile, as discussed above, does not justify indiscriminate administration of inhaled glucocorticoids in COPD. Fixed combinations of inhaled glucocorticoids and long-acting $\beta_{2}$-agonists, namely fluticasone-salmeterol (Dransfiel and Bailey 2004) and budesonide-formoterol, were approved for use in COPD in the US and other countries based on clinical trials showing their effectiveness for health status and exacerbations of COPD (Calverley, Boonsawat, et al 2003; Calverley, Pauwels, et al 2003; Szafranski et al 2003). However, there were conflicting results when the different combination therapies were compared with the mono-component alone (Nannini et al 2004). More studies to definitively establish the effects of combination therapy in a single inhaler are required, including double-dummy trials on the comparative effects with separate adiministration of the two drugs (Nannini et al 2004).

\section{Other drugs}

\section{Vaccines}

Vaccination can reduce severe complications and mortality from influenza in elderly patients, including those with COPD. Vaccination is recommended once in the autumn or, once in the autumn and once in the winter each year (Nichol et al 1994; Hak et al 1998). Pneumococcal vaccines have been used in COPD patients and can reduce complications of pneumonia in elderly patients, but there is no evidence to support its general use in COPD patients.

\section{Antibiotics}

Numerous large-scale controlled studies have shown that prophylactic antibiotics and chronic antibiotic administration have no effect on the frequency of exacerbations in COPD (MacNee and Calverley 2003). Prophylactic antibiotics are also ineffective in winter (MacNee and Calverley 2003). Current available data does not support the effectiveness of prophylactic antibiotics against bacterial infections or exacerbations of COPD.

\section{Mucolytic agents}

Mucolytic agents such as ambroxol, erdosteine, carbocysteine, and iodinated glycerol produce a reduction in the frequency of exacerbations in chronic bronchitis compared with a placebo (Poole and Black 2000). Since these studies are of relatively short duration, between two to six months, and in patients with mild to moderate $\mathrm{COPD}\left(\mathrm{FEV}_{1}>50 \%\right.$ of the predicted value), the systematic administration of mucolytic drugs in COPD is not currently recommended.

\section{Antioxidants}

Oxidant stress plays an important role in the pathophysiology of COPD. Therefore, administration of antioxidant agents is an interesting treatment strategy. Although antioxidant and mucolytic drug $\mathrm{N}$-acetylcysteine has been shown to reduce the frequency of exacerbations of COPD in most clinical trials (Grandjean et al 2000), a recent 3 year randomized placebo-controlled multicenter trial has shown that $\mathrm{N}$ acetylcysteine is ineffective at prevention of deterioration in lung function and prevention of exacerbations in patients with COPD (Decramer et al 2005). On the basis of current data, $\mathrm{N}$-acetylcysteine is not recommended for COPD (MacNee and Calverley). The details of various antioxidants trials are discussed elsewhere (Rahman 2006).

\section{Drugs in phase III of clinical development Phosphodiesterase-4 inhibitors}

Selective inhibitors of phosphodiesterase (PDE) type 4 increase intracellular concentrations of cyclic AMP by inhibiting its breakdown with consequent airway smooth muscle relaxation and anti-inflammatory effects on effector cells involved in the pathophysiology of COPD (Lipworth 2005). PDE4 enzymes include at least four isoenzymes (PDE4A, PDE4B, PDE4C, and PDE4D) (Soderling and Beavo 2000). Inhibition of PDE4B is mainly responsible for the anti-inflammatory effects of PDE4 inhibitors, whereas inhibition of PDE4D causes nausea which is one of the main adverse effects of these drugs (Lipworth 2005). Cilomilast and roflumilast, the two main orally active PDE4 inhibitors, are in the late phase III of clinical development for COPD (Lipworth 2005). Placebo-controlled studies for up to 6 months with cilomilast $15 \mathrm{mg}$ twice daily and roflumilast $500 \mathrm{mg}$ once daily have shown small, although significant, improvements in lung function tests in patients with COPD (Compton et al 2001; Rabe et al 2005). PDE4 inhibitors 
also reduce the rate of COPD exacerbations compared with placebo (Rabe et al 2005; Rennard et al 2006). The effect of PDE4 inhibitors on health status in patients with COPD is variable possibly due to differences in the duration of treatment (Compton et al 2001; Rabe et al 2005; Rennard et al 2006). Cilomilast at a dose of $15 \mathrm{mg}$ twice daily for 12 weeks reduces CD4+ T-lymphocyte subsets and CD68+ macrophages in bronchial biopsies from patients with COPD (Gamble et al 2003). However, whether these changes in airway inflammation are related to clinical outcomes in patients with COPD is unknown (Lipworth 2005). The main adverse effects of PDE4 inhibitors are nausea, diarrhea, and abdominal pain (Lipworth 2005). Roflumilast is more tolerated than cilomilast as it has similar selectivity for PDE4 isoenzymes, whereas cilomilast is 10 times more selective for PDE4D than other isoenzymes (Manning et al 1999; Hatzelmann and Schudt 2001). Long-term studies are required to definitively establish the effects of PDE4 inhibitors on clinical outcomes, including lung function, exacerbation rate, and health status in patients with COPD.

\section{Treatment of exacerbations of COPD}

According to a recent definition, exacerbations of COPD are "a variation in symptoms above the normal day to day variation which causes a change in a patient's medication” (Rodriguez-Roisin 2000). Exacerbations of COPD worsen general health status (Seemungal et al 1998) and are considerably expensive. The number of exacerbations is related to disease severity. Patients with moderate to severe COPD have one or two exacerbations per year (Seemungal et al 1998; Burge et al 2000). Many factors determine the type of treatment used and where the treatment is carried out, for example, in an outpatient or hospital setting.

The severity of the exacerbations is related to the severity of the disease. In patients with mild COPD, exacerbations are associated with increased breathlessness accompanied by cough and sputum production. They may often be managed out of hospital. Exacerbations of severe COPD are often associated with respiratory failure which may be fatal and require hospital admission on a general ward or intensive care unit. Exacerbations are caused by bacterial or viral infections in around 50\% of cases (Monso et al 1995; Soler et al 1998; Seemungal et al 2000). Other factors such as air pollution and temperature may cause exacerbations (MacNee 2002). However, it is not possible to identify a cause in about one third of exacerbations of COPD (Connors et al 1996). One of the main problems is the decision to treat exacerbations of COPD at home or in hospital. This decision is influenced by the severity of symptoms, the severity of COPD, and whether hospital admission is required. Recent trials have shown that about $30 \%$ of patients admitted to hospital with exacerbations of COPD could be adequately treated at home with immediate or early discharge and nurse-led home care (Skwarska et al 2000; Cotton et al 2000; Davies et al 1999, 2000). Patients prefer this form of treatment, which has been widely adapted to facilitate the discharge of those patients initially requiring hospitalization (Cotton et al 2000; Ojoo et al 2002). However, a clinical trial showed that home care did not improve the health of the patients whilst increasing costs compared with admission to hospital (Shepperd, Harwood, Gray, et al 1998; Shepperd, Harwood, Jenkinson, et al 1998).

\section{Home treatment}

The algorithm shown in Figure 3, which is based on a stepwise therapeutic approach (Sachs 1981; ATS 1995; Siafakas et al 1995; Celli 1996; Shepperd, Harwood, Jenkinson, et al 1998), may be used in the home treatment of exacerbations of COPD using bronchodilators, if necessary delivered by nebulizer, or antibiotics if symptoms indicate a bacterial infection, and oral glucocorticoids in moderate to severe exacerbations. The dose and/or frequency of bronchodilator delivery must be increased or bronchodilator treatment must be started if these drugs have not been used previously. Administration of high doses of antimuscarinics on demand delivered for a number of days using a nebulizer may be useful, even though chronic nebulizer treatment is not generally recommended after an exacerbation (GICOPD 2001). Systemic glucocorticoids are effective for exacerbations of COPD as they facilitate clinical improvement and lung function (Thompson et al 1996; Niewoehner et al 1999; Cotton et al 2000) and are recommended for patients with moderate to severe exacerbations of COPD when the baseline $\mathrm{FEV}_{1}$ is less than $50 \%$ of the predicted value (GICOPD 2001). The optimum dose and duration of treatment is not known, but administration of oral prednisolone at $40 \mathrm{mg}$ per day for ten days is generally effective (GICOPD 2001). Nebulized budesonide is as effective as oral glucocorticoids in improving lung function. However, it is not clear whether the increased costs of inhaled glucocorticoids are justified in all cases (Maltais et al 2002). Antibiotic treatment, which does not generally require parenteral administration, is recommended if two or more of the following symptoms are present: increasing dyspnoea, increasing sputum purulence, or increasing sputum volume (Anthonisen et al 1987). Antibiotics should be chosen which are effective against Streptococcus pneumoniae, Haemophilus influenzae, and Moraxella catarrhalis. These 
are the bacteria that most frequently cause exacerbations of COPD. However, the choice of antibiotics must be based on the antibiogram (GICOPD 2001).

\section{Hospital treatment}

The criteria for necessary hospital treatment, whether during admission to the emergency department, or during hospitalization, for exacerbations of COPD are described in the GOLD guidelines (GICOPD 2001). Hospital treatment is increasingly focused on the management of lung function and associated complications, particularly considering the increased number of early discharges (MacNee and Calverley 2003). Firstly, it is necessary to establish whether the exacerbation of COPD may be life-threatening and if this is the case the patients must be admitted to intensive care. The risk of mortality from exacerbations of COPD is connected with the level of respiratory acidosis, the presence of concomitant diseases, and the need for assisted ventilation (Connors et al 1996). In the absence of these characteristics, the risk of mortality is low, even though patients with severe COPD require hospitalization (GICOPD 2001). In these cases the effectiveness of home treatment is poor (Shepperd, Harwood, Gray, et al 1998). However, the results are better if home treatment follows a careful assessment in the emergency department and is combined with adequate doctor- or nurse-administered home care (Gravil et al 1998). Controlled oxygen therapy is the cornerstone of hospital treatment of exacerbations of COPD (GICOPD 2001). It is relatively easy to achieve adequate oxygenation $\left(\mathrm{PaO}_{2}>60 \mathrm{mmHg}\right.$ or $\left.\mathrm{SaO}_{2}>90 \%\right)$ in uncomplicated exacerbations, but $\mathrm{CO}_{2}$ retention can occur (GICOPD 2001). $\beta_{2}$-agonists are the main bronchodilators used for the treatment of exacerbations of COPD (Siafakas et al 1995; Celli 1996; BTS 1997). If rapid bronchodilation does not occur with these drugs, an antimuscarinic agent may be administered, even if the effectiveness of this combination is controversial (Fernandez et al 1994; Moayyedi et al 1995). The role of theophylline in the treatment of exacerbations of

Start or increase treatment with bronchodilators,

consider antibiotics

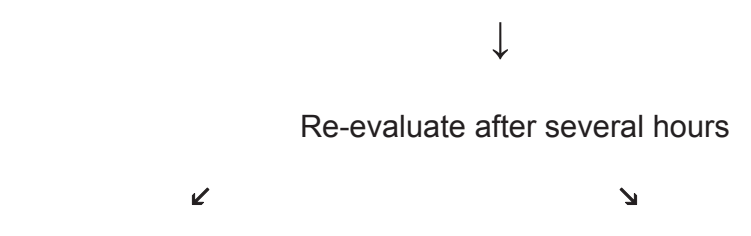

Resolution or improvement

No improvement

of symptoms

or resolution

$\downarrow$

Continue the treatment,

with reduction if possible

$\downarrow$

Review the chronic treatment

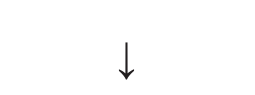

Oral glucocorticoids

Re-evaluate after several hours

$\downarrow$

Worsening of symptoms

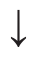

Admission to hospital

Figure 3 Algorithm for the home treatment of an exacerbation of COPD (adapted from Global Initiative for Chronic Obstructive Lung Disease. 200I. Global strategy for the diagnosis, management, and prevention of chronic obstructive pulmonary disease. National Institutes of Health. National Heart, Lung, and Blood Institute. Publication number 2701). 
COPD is also controversial (GICOPD 2001). Theophylline leads to modest improvements in lung function without gas exchange deterioration (Barbera et al 1992; Mahon et al 1999). Administration of intravenous theophylline can be considered in more severe exacerbations (GICOPD 2001) although the available data do not support the use of methylxanthines for the treatment of exacerbations of COPD (Barr et al 2003). However, this requires close monitoring of the plasma concentrations to avoid the occurrence of dosedependent toxic effects (Lloberes et al 1988; Emerman et al 1990; Barbera et al 1992). Oral or intravenous glucocorticoids are recommended with bronchodilator therapy and, if necessary, antibiotics and oxygen therapy, for treatment in hospital of exacerbations of COPD (Thompson et al 1996; Davies et al 1999; Niewoehner et al 1999; GICOPD 2001). The optimum dose of glucocorticoids is not known, but high doses increase the risk of significant side effects. Generally $30 \mathrm{mg}$ to $40 \mathrm{mg}$ of oral prednisolone is administered for 10 to 14 days (GICOPD 2001). Prolonged treatment does not improve efficacy, while increasing the risk of side effects. Antibiotics are only effective when exacerbations also occur with sputum purulence and increased sputum volume and/or fever, indicating a bacterial infection (Anthonisen et al 1987). Antibiotics must be effective against Streptococcus pneumoniae, Haemophilus influenzae, and Moraxella catarrhalis. These are the bacterial microorganisms most frequently involved in exacerbations of COPD. However, the choice of antibiotics must be based on the antibiogram. Toxicity due to excessive oxygen therapy in the emergency department is still a prevalent problem which could be resolved by increasing patient awareness of the risk (Plant et al 2000a). In cases of severe exacerbations of COPD (stage III) mechanical ventilation is required which may be invasive (conventional) or non-invasive with the aim of reducing morbidity and mortality and improving symptoms. Non-invasive positive pressure ventilation (NIPPV) is an effective alternative to conventional mechanical ventilation in the intensive care unit and is even applicable in the general ward with specialized nursing staff (Brochard et al 1995; Plant et al 2000a). NIPPV reduces patient morbidity and length of stay in hospital by preventing the onset of nosocomial pneumonia, but it is less effective than intermittent positive pressure ventilation in patients with a $\mathrm{pH}$ persistently $<7.30$ (Plant et al 2000b).

\section{Conclusions}

Pharmacological treatment of COPD is currently symptomatic and is based on inhaled bronchodilators such as anticholinergics, selective $\beta_{2}$-adrenergic agonists and theophylline. In the absence of proven efficacy and due to higher costs and side effects, glucocorticoids are not generally recommended for stable COPD, though they are effective in the treatment of exacerbations. In the absence of drugs which reduce progressive decline in lung function, which is the hallmark of this disease, cessation of cigarette smoking, the main risk factor for COPD, is the most effective measure. Numerous studies are being carried out to define the pathophysiology of COPD, about which still relatively little is known. It is hoped that these studies will allow new and effective drugs to be discovered and developed, as the current pharmacological treatment of COPD is inadequate.

\section{Acknowledgments}

This report has been partly produced using faculty funds 2005-2006 from the Catholic University of the Sacred Heart in Rome.

\section{References}

Aaron SD, Vandemheen K, Fergusson D, et al. 2004. The Canadian Optimal Therapy for COPD trial: design, organization and patient recruitment. Can Respir J, 11:581-5.

[ATS] American Thoracic Society. 1995. Standards for the diagnosis and care of patients with chronic obstructive pulmonary disease. Am J Respir Crit Care Med, 152:S77-121.

Anthonisen NR, Connett JE, Kiley JP, et al. 1994. Effects of smoking intervention and the use of an inhaled anticholinergic bronchodilator on the rate of decline of $\mathrm{FEV}_{1}$. The Lung Health Study. JAMA, 272:1497-505.

Anthonisen NR, Manfreda J, Warren CP, et al. 1987. Antibiotic therapy in exacerbations of chronic obstructive pulmonary disease. Ann Intern Med, 106:196-204.

Barbera JA, Reyes A, Roca J, et al. 1992. Effect of intravenously administered aminophylline on ventilation/perfusion inequality during recovery from exacerbations of chronic obstructive pulmonary disease. Am Rev Respir Dis, 145:1328-33.

Barnes PJ. 1999. Effect of $\beta$-agonists on inflammatory cells. J Allergy Clin Immunol, 104:S10-17.

Barnes PJ. 2000. Inhaled corticosteroids are not beneficial in chronic obstructive pulmonary disease. Am J Respir Crit Care Med, 161:342-4.

Barnes PJ. 2003. Theophylline: new perspectives for an old drug. Am J Respir Crit Care Med, 167:813-18.

Barnes PJ. 2006. Theophylline for COPD. Thorax, 61:742-4.

Bellia V, Foresi A, Bianco S, et al. 2002. Efficacy and safety of oxitropium bromide, theophylline and their combination in COPD patients: a double-blind, randomised, multicentre study. Respir Med, 96:881-9.

Belman MJ, Botnick WC, Shin JW. 1996. Inhaled bronchodilators reduce dynamic hyperinflation during exercise in patients with chronic obstructive pulmonary disease. Am J Respir Crit Care Med, 153:967-75.

Berger R, Smith D. 1988. Effect of inhaled metaproterenol on exercise performance in patients with stable "fixed" airway obstruction. $A m$ Rev Respir Dis, 138:624-9.

Bleecker ER, Britt EJ. 1991. Acute bronchodilating effects of ipratropium bromide and theophylline in chronic obstructive pulmonary disease. Am J Med, 91:24-7.

Boyd G, Morice AH, Pounsford JC, et al. 1997. An evaluation of salmeterol in the treatment of chronic obstructive pulmonary disease (COPD). Eur Respir J, 10:815-21. 
Brochard L, Manchebo J, Wysocki M, et al. 1995. Noninvasive ventilation for acute exacerbations of chronic obstructive pulmonary disease. N Engl J Med, 333:817-22.

[BTS] The COPD Guidelines Group of the Standards of Care Committee of the BTS. 1997. BTS guidelines for the management of chronic obstructive pulmonary disease. Thorax, 52(Suppl 5):S1-28.

Burge PS, Calverley PM, Jones PW, et al. 2000. Randomised, double blind, placebo controlled study of fluticasone propionate in patients with moderate to severe chronic obstructive pulmonary disease: the ISOLDE trial. $B M J, 320: 1297-1303$.

Burge PS, Calverley PM, Jones PW, et al. 2003. Prednisolone response in patients with chronic obstructive pulmonary disease: results from the ISOLDE study. Thorax, 58:654-8.

Calverley PM. 2000. The future for tiotropium. Chest, 117(2 Suppl):67S69S.

Calverley PM, Boonsawat W, Cseke Z, et al. 2003. Maintenance therapy with budesonide and formoterol in chronic obstructive pulmonary disease. Eur Respir J, 22:912-19.

Calverley P, Pauwels R, Vestbo J, et al. 2003. Combined salmeterol and fluticasone in the treatment of chronic obstructive pulmonary disease: a randomised control trial. Lancet, 361:449-56.

Casaburi R, Kukafka D, Cooper CB, et al. 2005. Improvement in exercise tolerance with the combination of tiotropium and pulmonary rehabilitation in patients with COPD. Chest, 127:809-17.

Casaburi R, Mahler DA, Jones PW, et al. 2002. A long-term evaluation of once-daily inhaled tiotropium in chronic obstructive pulmonary disease. Eur Respir J, 19:217-24.

Cazzola M, Matera MG, Santangelo G, et al. 1995. Salmeterol and formoterol in partially reversible severe chronic obstructive pulmonary disease a dose-response study. Respir Med, 89:357-62.

Celli BR. 1996. Current thoughts regarding treatment of chronic obstructive pulmonary disease. Med Clin North Am, 80:589-609.

Celli BR, McNee W. 2004. Standards for the diagnosis and treatment of patients with COPD: a summary of the ATS/ERS position paper. Eur Respir J, 23:932-46.

Chrystyn H, Mulley BA, Peake MD. 1988. Dose response relation to oral theophylline in severe chronic obstructive airways disease. $B M J$, 297:1506-10.

COMBIVENT Inhalation Aerosol Study Group. 1994. In chronic obstructive pulmonary disease, a combination of ipratropium and albuterol is more effective than either agent alone. An 85-day multicenter Trial. Chest, 105:1411-19.

Compton CH, Gubb J, Nieman R, et al; International Study Group. 2001. Cilomilast, a selective phosphodiesterase-4 inhibitor for treatment of patients with chronic obstructive pulmonary disease: a randomised, dose-ranging study. Lancet, 358:265-70.

Confalonieri M, Mainardi E, Della Porta R, et al. 1998. Inhaled corticosteroids reduce neutrophilic bronchial inflammation in patients with chronic obstructive pulmonary disease. Thorax, 53:583-5.

Connors AF Jr, Dawson NV, Thomas C, et al. 1996. Outcomes following acute exacerbation of severe chronic obstructive lung disease. The SUPPORT investigators (Study to Understand Prognoses and Preferences for Outcomes and Risks of Treatments). Am J Respir Crit Care Med, 154:959-67.

Cooper CB, Davidson AC, Cameron IR. 1987. Aminophylline, respiratory muscle strength and exercise tolerance in chronic obstructive airway disease. Bull Eur Physiopathol Respir, 23:15-22.

Cotton MM, Bucknall CE, Dagg KD, et al. 2000. Early discharge for patients with exacerbations of chronic obstructive pulmonary disease a randomized controlled trial. Thorax, 55:902-6.

Cuvelier A, Muir JF, Benhamou D, et al. 2002. Dry powder ipratropium bromide is as safe and effective as metered-dose inhaler formulation: a cumulative dose-response study in chronic obstructive pulmonary disease patients. Respir Care, 47:159-66.

Davies L, Angus RM, Calverley PM. 1999. Oral corticosteroids in patients admitted to hospital with exacerbations of chronic obstructive pulmonary disease: a prospective randomised controlled trial. Lancet, 354:456-60.
Davies L, Wilkinson M, Bonner S, et al. 2000. "Hospital at home" versus hospital care in patients with exacerbations of chronic obstructive pulmonary disease: prospective randomised controlled trial. $B M J$, 321:1265-8.

Decramer M, Rutten-van Molken M, Dekhuijzen PN, et al. 2005. Effects of $\mathrm{N}$-acetylcysteine on outcomes in chronic obstructive pulmonary disease (Bronchitis Randomized on NAC Cost-Utility Study, BRONCUS): a randomised placebo-controlled trial. Lancet, 365:1552-60.

Dransfield MT, Bailey WC. 2004. Fluticasone propionate/salmeterol for the treatment of chronic-obstructive pulmonary disease. Expert Opin Pharmacother, 5:1815-26.

Edelson JD, Compton C, Nieman R, et al. 2001. Cilomilast Ariflo a potent, selective phosphodiesterase-4 inhibitor for treatment of patient with chronic obstructive pulmonary disease: results of 6-month trial. Am J Respir Crit Care Med, 163:A771.

Emerman CL, Connors AF, Lukens TW, et al. 1990. Theophylline concentrations in patients with acute exacerbations of COPD. Am J Emerg Med, 8:289-92.

Fan VS, Bryson CL, Curtis JR, et al. 2003. Inhaled corticosteroids in chronic obstructive pulmonary disease and risk of death and hospitalisation time-dependent analysis. Am J Respir Crit Care Med, 168:1488-94.

Feoktistov I, Polosa R, Holgate ST, et al. 1998. Adenosine A2B receptors: a novel therapeutic target in asthma? Trends Pharmacol Sci, 19:148-53

Fernandez A, Munoz J, de la Calle B, et al. 1994. Comparison of one versus two bronchodilators in ventilated COPD patients. Intensive Care Med, 20:199-202.

Gamble E, Grootendorst DC, Brightling CE, et al. 2003. Anti-inflammatory effects of the phosphodiesterase-4 inhibitor cilomilast (Ariflo) in chronic obstructive pulmonary disease. Am J Respir Crit Care Med, 168:976-82

[GICOPD] Global Initiative for Chronic Obstructive Lung Disease. 2001. Global strategy for the diagnosis, management, and prevention of chronic obstructive pulmonary disease. National Institutes of Health. National Heart, Lung, and Blood Institute. Publication number 2701.

Grandjean EM, Berthet P, Ruffmann R, et al. 2000. Efficacy and oral long-term $\mathrm{N}$-acetylcysteine in chronic bronchopulmonary disease: a meta-analysis of published double-blind, placebo-controlled clinical trials. Clin Ther, 22:209-21.

Gravil JH, Al-Rawas OA, Cotton MM, et al. 1998. Home treatment of exacerbations of chronic obstructive pulmonary disease by an acute respiratory assessment service. Lancet, 351:1853-5.

Gross NJ, Petty TL, Friedman M, et al. 1989. Dose response to ipratropium as a nebulized solution in patients with chronic obstructive pulmonary disease. A three-center study. Am Rev Respir Dis, 139:1188-91.

Hak E, van Essen GA, Buskens E, et al. 1998. Is immunising all patients with chronic lung disease in the community against influenza cost effective? Evidence from a general practice based clinical prospective cohort study in Utrecht, The Netherlands. J Epidemiol Community Health, 52:120-5.

Hatzelmann A, Schudt C. 2001. Anti-inflammatory and immunomodulatory potential of the novel PDE4 inhibitor roflumilast in vitro. J Pharmacol Exp Ther, 297:267-79.

Hay JG, Stone P, Carter J, et al. 1992. Bronchodilator reversibility, exercise performance and breathlessness in stable chronic obstructive pulmonary disease. Eur Respir J, 5:659-64.

Hughes JM, Seale JP, Temple DM. 1983. Effect of fenoterol on immunological release of leukotrienes and histamine from human lung in vitro: selective antagonism by beta-adrenoceptor antagonists. Eur $J$ Pharmacol, 95:239-45.

Ikeda A, Nishimura K, Koyama H, et al. 1999. Comparison of the bronchodilator effects of salbutamol delivered via a metered-dose inhaler with spacer, a dry-powder inhaler, and a jet nebulizer in patients with chronic obstructive pulmonary disease. Respiration, 66:119-23.

Johnson M, Coleman RA. 1995. Mechanisms of action of $\beta_{2}$ adrenoceptor agonists. In: Busse WW, Holgate ST (ed). Asthma and rhinitis. Cambridge: Balckwell Sci Pub, 1278-95. 
Johnson M, Rennard S. 2001. Alternative mechanisms for long-acting $\beta_{2}$-agonists in COPD. Chest, 120:258-70.

Jones PW, Willits LR, Burge PS, et al. 2003. Disease severity and effect of fluticasone propionate on chronic obstructive pulmonary disease exacerbations. Eur Respir J, 21:68-73.

Jorenby DE, Leischow SJ, Nides MA, et al. 1999. A controlled trial of sustained-release bupropion, a nicotine patch, or both for smoking cessation. $N$ Engl J Med, 340:685-91.

Keatings VM, Jatakanon A, Worsdell YM, et al. Effects of inhaled and oral glucocorticoids on inflammatory indices in asthma and COPD. Am J Respir Crit Care Med, 155:542-8.

Kirsten DK, Wegner RE, Jorres RA, et al. 1994. Effects of theophylline withdrawal in severe chronic obstructive pulmonary disease. Chest, 104:1101-7.

Kume H, Hall IP, Washabau RJ, et al. 1994. Beta-adrenergic agonists regulate $\mathrm{KCa}$ channels in airway smooth muscle by cAMP-dependent and -independent mechanisms. $J$ Clin Invest, 93:371-9.

Lipworth BJ. 2005. Phosphodiesterase-4 inhibitors for asthma and chronic obstructive pulmonary disease. Lancet, 365:167-75.

[LHSRG] The Lung Health Study Research Group II. 2000. Effect of inhaled triamcinolone on the decline in pulmonary function in chronic obstructive pulmonary disease. $N$ Engl J Med, 343:1902-9.

Lloberes P, Ramis L, Montserrat JM, et al. 1988. Effect of three different bronchodilators during an exacerbation of chronic obstructive pulmonary disease. Eur Respir J, 1:536-9.

MacNee W. 2002. Acute exacerbations of COPD. Consensus conference on management of chronic obstructive pulmonary disease. $J R$ Coll Physicians Edinb, 32:16-26.

MacNee W, Calverley PM. 2003. Chronic obstructive pulmonary disease. 7: Management of COPD. Thorax, 58:261-5.

Mahler DA, Donohue JF, Barbee RA, et al. 1999. Efficacy of salmeterol xinafoate in the treatment of COPD. Chest, 115:957-65.

Mahler DA, Wire P, Horstman D, et al. 2002. Effectiveness of fluticasone propionate and salmeterol combination delivered via the diskus device in the treatment of chronic obstructive pulmonary disease. Am J Respir Crit Care Med, 166:1084-91.

Mahon JL, Laupacis A, Hodder RV, et al. 1999. Theophylline for irreversible chronic airflow limitation: a randomized study comparing $\mathrm{n}$ of 1 trials to standard practice. Chest, 115:38-48.

Maltais F, Ostinelli J, Bourbeau J, et al. 2002. Comparison of nebulized budesonide and oral prednisolone with placebo in the treatment of acute exacerbations of chronic obstructive pulmonary disease: a randomized controlled trial. Am J Respir Crit Care Med, 165:698-703.

Manning CD, Burman M, Christensen SB, et al. 1999. Suppression of human inflammatory cell function by subtype-selective PDE4 inhibitors correlates with inhibition of PDE4A and PDE4B. Br J Pharmacol, 128:1393-8

McKay SE, Howie CA, Thomson AH, et al. 1993. Value of theophylline treatment in patients handicapped by chronic obstructive lung disease. Thorax, 48:227-32.

McNicholas WT, Calverley PM, Lee A, 2004. Long-acting inhaled anticholinergic therapy improves sleeping oxygen saturation in COPD. Eur Respir J, 23:825-31.

Moayyedi P, Congleton J Page RL, et al. 1995. Comparison of nebulised salbutamol and ipratropium bromide with salbutamol alone in the treatment of chronic obstructive pulmonary disease. Thorax, 50:834-7.

Monso E, Ruiz J, Rosell A, et al. 1995. Bacterial infection in chronicobstructive pulmonary disease. A study of stable and exacerbated outpatients using the protected specimen brush. Am J Respir Crit Care Med, 152:1316-20.

Mulloy E, McNicholas WT. 1993. Theophylline improves gas exchange during rest, exercise, and sleep in severe chronic obstructive pulmonary disease. Am Rev Respir Dis, 148:1030-6.

Murciano D, Aubier M, Lecocguic Y, et al. 1984. Effects of theophylline on diaphragmatic strength and fatigue in patients with chronic obstructive pulmonary disease. $N$ Engl J Med, 311:349-53.
Murciano D, Auclair MH, Pariente R, et al. 1989. A randomized, controlled trial of theophylline in patients with severe chronic obstructive pulmonary disease. $N$ Engl J Med, 320:1521-5.

Nannini L, Cated CJ, Lasserson TJ, et al. 2004. Combined corticosteroid and long acting $\beta$-agonist in one inhaler for chronic obstructive pulmonary disease. Cochrane Database Syst Rev, 3:CD003794.

Nichol KL, Margolis KL, Wuorenma J, et al. 1994. The efficacy and cost effectiveness of vaccination against influenza among elderly persons living in the community. $N$ Engl J Med, 331:778-84.

Niewoehner DE, Erbland ML, Deupree RH, et al. 1999. Effect of systemic glucocorticoids on exacerbations of chronic obstructive pulmonary disease. Department of Veterans Affairs Cooperative Study Group. N Engl J Med, 340:1941-7.

Nishimura K, Koyama H, Ikeda A, et al. 1995. The additive effect of theophylline on high-dose combination of inhaled salbutamol and ipratropium bromide in stable COPD. Chest, 107:718-23.

[NPG] The Nebuliser Project Group of the British Thoracic Society Standards and Care Committee. 1997. BTS Guidelines on current best practice for nebuliser treatment. Thorax, 52(Suppl. 2):S1-106.

Ojoo JC, Moon T, McGlone S, et al. 2002. Patients' and carers' preferences in two models of care for acute exacerbations of COPD: results of a randomised controlled trial. Thorax, 57:167-9.

Paggiaro PL, Dahle R, Bakran I, et al. 1998. Multicentre randomised placebo-controlled trial of inhaled fluticasone propionate in patients with chronic obstructive pulmonary disease. International COPD Study Group. Lancet, 351:773-80.

Pauwels RA, Lofdahl CG, Laitinen LA, et al. 1999. Long-term treatment with inhaled budesonide in persons with mild chronic obstructive pulmonary disease who continue smoking. European Respiratory Society Study on Chronic Obstructive Pulmonary Disease. $N$ Engl J Med, 340:1948-53.

Plant PK, Owen JL, Elliott MW. 2000a. One year period prevalence study of respiratory acidosis in acute exacerbations of COPD: implications for the provision of non-invasive ventilation and oxygen administration. Thorax, 55:550-4.

Plant PK, Owen JL, Elliott MW. 2000b. Early use of non-invasive ventilation for acute exacerbations of chronic obstructive pulmonary disease on general respiratory wards: a multicenter randomised controlled trial. Lancet, 355:1931-5.

Poole PJ, Black PN. 2000. Mucolytic agents for chronic bronchitis or chronic obstructive pulmonary disease. Cochrane Database Syst Rev, 2:CD001287

Rabe KF, Bateman ED, O'Donnell D, et al. 2005. Roflumilast - an oral anti-inflammatory treatment for chronic obstructive pulmonary disease: a randomized controlled trial. Lancet, 366:563-71.

Rahman I. 2006. Antioxidant therapies in COPD. Int J COPD, 1:15-31.

Rennard SI. 2004. Treatment of stable chronic obstructive pulmonary disease. Lancet, 364:791-802.

Rennard SI, Anderson W, ZuWallack R, et al. 2001. Use of a long-acting inhaled $\beta_{2}$-adrenergic agonist, salmeterol xinafoate, in patients with chronic obstructive pulmonary disease. Am J Respir Crit Care Med, 163:1087-92.

Rennard SI, Schachter N, Strek M, et al. 2006. Cilomilast for COPD: results of a 6-month, placebo-controlled study of a potent, selective inhibitor of phosphodiesterase 4. Chest, 129:56-66.

Rodriguez-Roisin R. 2000. Toward a consensus definition for COPD exacerbations. Chest, 117(Suppl 2):398-401S.

[RS] Respiratory system. 2003. In: British National Formulary, 45th ed. London: Pharmaceutical Pr, 131-65.

Sachs FL. 1981. Chronic bronchitis. Clin Chest Med, 2:79-89.

Seale JP. 1988. Whither $\beta$-adrenoceptor agonists in the treatment of asthma. Prog Clin Biol Res, 263:367-77

Seemungal TA, Donaldson GC, Paul EA, et al. 1998. Effect of exacerbation on quality of life in patients with chronic obstructive pulmonay disease. Am J Respir Crit Care Med, 157:1418-22. 
Seemungal TA, Harper-Owen R, Bhowmik A, et al. 2000. Detection of rhinovirus in induced sputum at exacerbation of chronic obstructive pulmonary disease. Eur Respir $J$, 16:677-83.

Senderovitz T, Vestbo J, Frandsen J, et al. 1999. Steroid reversibility test followed by inhaled budesonide or placebo in outpatients with stable chronic obstructive pulmonary disease. The Danish Society of Respiratory Medicine. Respir Med, 93:715-18.

Shepperd S, Harwood D, Gray A, et al. 1998. Randomised controlled trial comparing hospital at home care with inpatient hospital care. II: cost minimisation analysis. $B M J, 316: 1791-6$.

Shepperd S, Harwood D, Jenkinson C, et al. 1998. Randomised controlled trial comparing hospital at home care with inpatient hospital care. I: three month follow up of health outcomes. BMJ, 316:1786-91.

Siafakas NM, Vermeire P, Pride NB, et al. 1995. Optimal assessment and management of chronic obstructive pulmonary disease (COPD). The European Respiratory Society Task Force. Eur Respir J, 8:1398-420.

Sin DD, Tu JV. 2001. Inhaled corticosteroids and the risk of mortality and readmission in elderly patients with chronic obstructive pulmonary disease. Am J Respir Crit Care Med, 164:580-4.

Sin DD, Wu L, Anderson JA, et al. 2005. Inhaled corticosteroids and mortality in chronic obstructive pulmonary disease. Thorax, 60:992-7.

Skwarska E, Cohen G, Skwarski KM, et al. 2000. Randomized controlled trial of supported discharge in patients with exacerbations of chronic obstructive pulmonary disease. Thorax, 55:907-12.

Soderling SH, Beavo JA. 2000. Regulation of cAMP and cGMP signaling: new phosphodiesterases and new functions. Curr Opin Cell Biol, 12:174-9.

Soler N, Torres A, Ewig S, et al. 1998. Bronchial microbial patterns in severe exacerbations of chronic obstructive pulmonary disease (COPD) requiring mechanical ventilation. Am J Respir Crit Care Med, 157:1498-505.

Soriano JB, Vestbo J, Pride NB, et al. 2002. Survival in COPD patients after regular use of fluticasone propionate and salmeterol in general practice. Eur Respir J, 20:819-25.

Suissa F. 2003. Effectiveness of inhaled corticosteroids in chronic obstructive pulmonary disease: immortal time bias in observational studies. Am J Respir Crit Care Med, 168:49-53.

Szafranski W, Cukier A, Ramirez A, et al. 2003. Efficacy and safety of budesonide/formoterol in the management of chronic obstructive pulmonary disease. Eur Respir J, 21:74-81.
Tashkin D, Kanner R, Bailey W, et al. 2001. Smoking cessation in patients with chronic obstructive pulmonary disease: a double-blind, placebocontrolled, randomised trial. Lancet, 357:1571-5.

Thompson WH, Nielson CP, Carvalho P, et al. 1996. Controlled trial of oral prednisone in outpatients with acute COPD exacerbation. Am J Respir Crit Care Med, 154:407-12.

Torphy TJ, Undem BJ, Cieslinski LB, et al. 1993. Identification, characterization and functional role of phosphodiesterase isozymes in human airway smooth muscle. J Pharmacol Exp Ther, 265:1213-23.

Ulrik CS. 1995. Efficacy of inhaled salmeterol in the management of smokers with chronic obstructive pulmonary disease: a single centre randomised, double blind, placebo controlled, crossover study. Thorax, 50:750-4.

Undem, JB, Lichtenstein LM. 2001. Drugs used in the treatment of asthma In: Hardman JG, Limbird LE, Goodman Gilman A (ed). The pharmacological basis of therapeutics. 10th edn. New York: McGraw-Hill, 733-54.

van Noord JA, Aumann JL, Janssens E, et al. 2006. Effects of tiotropium with and without formoterol on airflow obstruction and resting hyperinflation in patients with COPD. Chest, 129:509-17.

van Noord JA, de Munck DR, Bantje TA, et al. 2000. Long-term treatment of chronic obstructive pulmonary disease with salmeterol and the additive effect of ipratropium. Eur Respir J, 15:878-85.

van Schayck CP, Dompeling E, van Herwaarden CL, et al. 1991. Bronchodilator treatment in moderate asthma or chronic bronchitis: continuous or on demand? A randomised controlled study. $B M J$, 303:1426-31.

Vathenen AS, Britton JR, Ebden P, et al. 1988. High-dose inhaled albuterol in severe chronic airflow limitation. Am Rev Respir Dis, 138:850-5.

Vestbo J, Sorensen T, Lange P, et al. 1999. Long-term effect of inhaled budesonide in mild and moderate chronic obstructive pulmonary disease: a randomised controlled trial. Lancet, 353:1819-23.

Vestbo J; TORCH Study Group. 2004. The TORCH (towards a revolution in COPD health) survival study protocol. Eur Respir $J$, 24:206-10.

Wouters EF, Postma DS, Fokkens B, et al. 2005. Withdrawal of fluticasone propionate from combined salmeterol/fluticasone treatment in patients with COPD causes immediate and sustained disease deterioration: a randomized controlled trial. Thorax, 60:480-7. 
